\title{
The sound velocity of wüstite at high pressures: implications for low-velocity anomalies at the base of the lower mantle
}

\author{
Ryosuke Tanaka ${ }^{1}$, Tatsuya Sakamaki ${ }^{1 *} \mathbb{D}$, Eiji Ohtani ${ }^{1}$, Hiroshi Fukui ${ }^{2,3}$, Seiji Kamada ${ }^{1,4}$, Akio Suzuki $^{1}$, Satoshi Tsutsui ${ }^{5}$,
} Hiroshi Uchiyama ${ }^{5}$ and Alfred Q. R. Baron ${ }^{3}$

\begin{abstract}
The longitudinal sound velocity $\left(V_{P}\right)$ and the density $(\rho)$ of wüstite, FeO, were measured at pressures of up to 112.3 GPa and temperatures of up to $1700 \mathrm{~K}$ using both inelastic X-ray scattering and X-ray diffraction combined with a laser-heated diamond-anvil cell. The linear relationship between $V_{P}$ and $\rho$, Birch's law, for wüstite can be expressed as $V_{P}=1.55(1) \times \rho\left[\mathrm{g} / \mathrm{cm}^{3}\right]-2.03(8)[\mathrm{km} / \mathrm{s}]$ at $300 \mathrm{~K}$ and $V_{P}=1.61(1) \times \rho\left[\mathrm{kg} / \mathrm{m}^{3}\right]-2.82(10)[\mathrm{km} / \mathrm{s}]$ at $1700 \mathrm{~K}$. The sound velocity of wüstite is significantly lower than that of bridgmanite and ferropericlase under lower mantle conditions. In other words, the existence of wüstite in the lower mantle can efficiently decrease the seismic velocity. Considering its slow velocity and several mechanisms for the formation of FeO-rich regions at the coremantle boundary, we confirm earlier suggestions indicating that wüstite enrichment at the bottom of the Earth's mantle may contribute to the formation of denser ultra-low velocity zones.
\end{abstract}

Keywords: Wüstite, FeO, Sound velocity, High pressure, Inelastic X-ray scattering, Seismic low-velocity anomaly

\section{Introduction}

Wüstite, $\mathrm{FeO}$, is one of the most important oxides in the interior of the Earth because it is an endmember of ferropericlase, $(\mathrm{Mg}, \mathrm{Fe}) \mathrm{O}$, which is the second most dominant phase in the Earth's lower mantle. Wüstite has a B1 (NaCl-type) structure under ambient conditions. Under increasing pressure, it distorts into $\mathrm{rB1}$ (a rhombohedral distorted-B1 phase) at approximately $16 \mathrm{GPa}$ (e.g., Yagi et al. 1985), and a phase transition from $r B 1$ to a $B 8$ (NiAs-type) structure has been found at $96 \mathrm{GPa}$ and $800 \mathrm{~K}$ (e.g., Fei and Mao 1994). The phase transformation from $\mathrm{B} 8$ into a $\mathrm{B} 2$ (CsCl-type) structure has been observed, and the triple point for the $\mathrm{B} 1, \mathrm{~B} 8$, and $\mathrm{B} 2$ phases has been reported to be at $240 \mathrm{GPa}$ and $3800 \mathrm{~K}$ (Ozawa et al. 2011b). In $\mathrm{B} 8-\mathrm{FeO}$, an occurrence of iron spin crossover, inversenormal structural transition, and insulator-metal

\footnotetext{
* Correspondence: sakamaki@m.tohoku.ac.jp

'Department of Earth Science, Graduate School of Science, Tohoku University, Sendai, Miyagi 980-8578, Japan

Full list of author information is available at the end of the article
}

transition has been reported near $120 \mathrm{GPa}$ (Ozawa et al. 2011a). In addition, the metallization of $\mathrm{B} 1-\mathrm{FeO}$ has been found near $70 \mathrm{GPa}$ and $1900 \mathrm{~K}$ without any structural phase transition (Ohta et al. 2012).

Seismological studies reveal the density and the sound velocity within the interior of the Earth and allow us to discuss its heterogeneous structure. For example, ultralow velocity zones (ULVZs) at the core-mantle boundary (CMB) have been observed (e.g., Idehara et al. 2007; Hutko et al. 2009; Rost et al. 2010; Thorne and Garnero 2004). The thickness of ULVZs is $5-20 \mathrm{~km}$, and the $V_{P}$ and $V_{S}$ values in these zones decrease by $~ 5 \%-20 \%$ and $\sim 10 \%-30 \%$, respectively. Even though ULVZs are locally distributed, (e.g., under the Philippine-Kalimantan and East Australia regions (Idehara et al. 2007); the central and north Pacific (Hutko et al. 2009); and east of Australia (Rost et al. 2010)), some ULVZs are likely attributable to wüstite enrichment in the mantle (e.g., Knittle and Jeanloz 1991; Dobson and Brodholt 2005; Labrosse et al. 2007). One important phenomenon is the chemical reaction 
between the silicates in the lower mantle and the liquid outer core; indeed, the formation of $\mathrm{FeO}$ has been experimentally demonstrated using a laser-heated diamondanvil cell (LHDAC) (e.g., Knittle and Jeanloz 1991). Banded-iron formations (BIFs) in subducting slabs can also provide $\mathrm{FeO}$ to the lower mantle due to the reduction of the $\mathrm{Fe}_{3} \mathrm{O}_{4}$ components in BIFs (Dobson and Brodholt 2005). A crystallization of a very dense iron-rich layer has also been proposed via the basal magma ocean hypothesis (Labrosse et al. 2007). In addition, the decomposition of ferropericlase, $\left(\mathrm{Mg}_{0.05}, \mathrm{Fe}_{0.95}\right) \mathrm{O}$, into $\mathrm{FeO}$ and $\left(\mathrm{Mg}_{0.20}\right.$, $\left.\mathrm{Fe}_{0.80}\right) \mathrm{O}$ has been observed in LHDAC experiments (Ohta et al. 2014). Therefore, knowledge of the elasticity of wüstite under lower mantle conditions will allow a better understanding of ULVZs.

Sound velocity measurements of ferropericlase (e.g., Jackson et al. 2006; Lin et al. 2006) and magnesiowüstite (e.g., Wicks et al. 2010, 2017) have been reported. Ferropericlase, which is iron-poor $(\mathrm{Mg}, \mathrm{Fe}) \mathrm{O}$, undergoes a spin crossover, resulting in a volume reduction and a change in physical properties, such as the sound velocities and density (e.g., Jackson et al. 2006; Lin et al. 2006). In addition, the sound velocity of wüstite has been measured at room temperature using various methods, such as the rectangular parallelepiped resonance method (Sumino et al. 1980) and ultrasonic velocity measurements (Mizutani et al. 1972). For sound velocity measurements at high pressure, the combination of a diamond-anvil cell (DAC) and inelastic X-ray scattering (IXS) is a powerful technique (e.g., Badro et al. 2007). Even though the velocity of wüstite has been measured up to $90 \mathrm{GPa}$ (Badro et al. 2007), such measurements remain limited to ambient temperatures and hightemperature data are still unavailable. Here, we conduct IXS experiments using LHDAC to obtain the sound velocity of wüstite at high pressure and high temperature to understand possible implications for the low-velocity anomalies at the CMB.

\section{Methods/Experimental}

The starting sample was a wüstite powder made from a reduction of hematite in a gas-controlled electric furnace. The chemical composition of the powder sample was confirmed to be $\mathrm{Fe}_{0.92} \mathrm{O}$ based on the lattice parameter determined via X-ray diffraction (McCammon and Liu 1984). A symmetric-type DAC was used to generate the examined pressures. The culet sizes of the diamond anvils were $150-300 \mu \mathrm{m}$, depending on the target pressure. Tungsten or rhenium was used as a gasket with a drilled hole for a sample chamber. The thickness and diameter of the sample chamber were approximately one-fourth and one-third of the culet sizes, respectively. The initial thickness of the samples was approximately $10-20 \mu \mathrm{m}$. The samples were loaded between two layers of $\mathrm{NaCl}$ or $\mathrm{Al}_{2} \mathrm{O}_{3}$, which were used as the pressure medium and thermal insulator. The pressure mediums were $15-25 \mu \mathrm{m}$ thick.

IXS experiments were performed on the BL35XU beamline (Baron et al. 2000) at the SPring- 8 facility in Japan. The beam size was focused to $16 \mu \mathrm{m} \times 16 \mu \mathrm{m}$ using a pair of Kirkpatrick-Baez mirrors (Ishikawa et al. 2013). The Si (9 9 9) backscattering optics provided an incident photon energy of $17.79 \mathrm{keV}$ with an energy resolution of $3 \mathrm{meV}$ at full width at half maximum (FWHM). A $3 \times 4$ array of spherical analyzer crystals was set at the end of the horizontal arm to analyze the scattered X-rays with different scattering vectors. The momentum transfer, $Q=2 k_{0} \sin (2 \theta / 2)$, where $k_{0}$ is the wave number of the incident photons and $2 \theta$ is the scattering angle, was selected by rotating the spectrometer arm in the horizontal plane. The momentum resolution was set to an approximately $0.4 \mathrm{~nm}^{-1}$ full width using slits in front of the analyzers. In this study, IXS spectra were collected in the range of $Q=4.0-10.0 \mathrm{~nm}^{-1}$ at each experimental pressure. X-ray diffraction (XRD) patterns were also obtained under the same experimental conditions as IXS using a flat panel area detector installed at BL35XU. The experimental pressure was determined using the unit cell volume of wüstite determined via XRD and its equation of state (McCammon and Liu 1984; Stixrude and Lithgow-Bertelloni 2007; Fischer et al. 2011). The parameters used for the equation of state of $\mathrm{B} 1-\mathrm{FeO}$ are summarized in Table 1 . We also checked the experimental pressure using the equation of state of $\mathrm{NaCl}$ (B1, Matsui et al. 2012; B2, Sakai et al. 2011) and a diamond Raman gage (Akahama and Kawamura 2004). A portable laser heating system, COMPAT (Fukui et al. 2013), was installed on the beamline to generate high temperatures. This system enabled us to measure the IXS from the sample loaded in the DAC under high pressure and high-temperature conditions (Sakamaki et al. 2016; Sakairi et al. 2018; Takahashi et al. 2019). The average diameter of the hot spot was approximately $30 \mu \mathrm{m}$, which was larger than the size of the incident $\mathrm{X}$-ray beam. The typical temperature

Table 1 Equation of state parameters for B1-FeO

\begin{tabular}{ll}
\hline & $B 1-\mathrm{FeO}$ \\
\hline$V_{0}\left[\mathrm{~cm}^{3} / \mathrm{mol}\right]$ & $12.256^{\mathrm{a}}$ \\
$K_{0}[\mathrm{GPa}]$ & $149.4(10)^{\mathrm{b}}$ \\
$K_{0}{ }^{\prime}$ & $3.60(4)^{\mathrm{b}}$ \\
$\theta_{0}$ & $417^{\mathrm{c}}$ \\
$Y_{0}$ & $1.41(5)^{\mathrm{b}}$ \\
$q$ & $0.5^{\mathrm{b}}$ \\
\hline
\end{tabular}

${ }^{\mathrm{a} M c C a m m o n}$ and Liu (1984)

bFischer et al. (2011)

'Stixrude and Lithgow-Bertelloni (2007) 
Table 2 Experimental conditions and results of this study

\begin{tabular}{|c|c|c|c|c|c|}
\hline Run No. & Pressure [GPa] & Temperature $[\mathrm{K}]$ & Density $\left[\mathrm{g} / \mathrm{cm}^{3}\right]$ & $V_{\rho}[\mathrm{km} / \mathrm{s}]$ & $V_{S}[\mathrm{~km} / \mathrm{s}$ \\
\hline IXS220 & $4.1(2)$ & 300 & $5.61(3)$ & $6.56(16)$ & $3.16(19)$ \\
\hline IXS193 & $45.6(41)$ & 300 & $6.81(2)$ & $8.57(11)$ & $4.52(21)$ \\
\hline IXS228 & $103.9(23)$ & 300 & $7.93(5)$ & $10.14(16)$ & $5.25(19)$ \\
\hline IXS182 & $51.1(3)$ & $1700(200)$ & $6.75(1)$ & $7.99(17)$ & $3.61(21)$ \\
\hline IXS179 & $59.4(3)$ & $1700(200)$ & $6.94(1)$ & $8.53(37)$ & $4.18(40)$ \\
\hline IXS227 & $112.3(11)$ & $1700(200)$ & $7.90(1)$ & 9.86 (15) & 4.74 (18) \\
\hline
\end{tabular}

uncertainty was $200 \mathrm{~K}$ due to fluctuations during the IXS collection.

\section{Results and discussion}

The IXS spectra of wüstite were acquired in the pressure range from $4.1 \mathrm{GPa}$ to $112.3 \mathrm{GPa}$ and the temperature range from $300 \mathrm{~K}$ to $1700 \mathrm{~K}$. The experimental conditions and results are summarized in Table 2. All samples under the experimental conditions were identified as having the $\mathrm{B} 1$ phase based on their XRD patterns. The density of wüstite was calculated using the unit cell volume obtained via XRD at the same conditions as the IXS measurements. An example of the IXS spectra and XRD pattern at $59.4 \mathrm{GPa}$ and $1700 \mathrm{~K}$ is shown in Figs. 1 and 2, respectively. The IXS spectra are characterized by an elastic contribution centered at zero energy and inelastic contributions from the longitudinal acoustic (LA) mode of wüstite and the transverse acoustic (TA) mode from the diamond anvil. Each peak energy position of

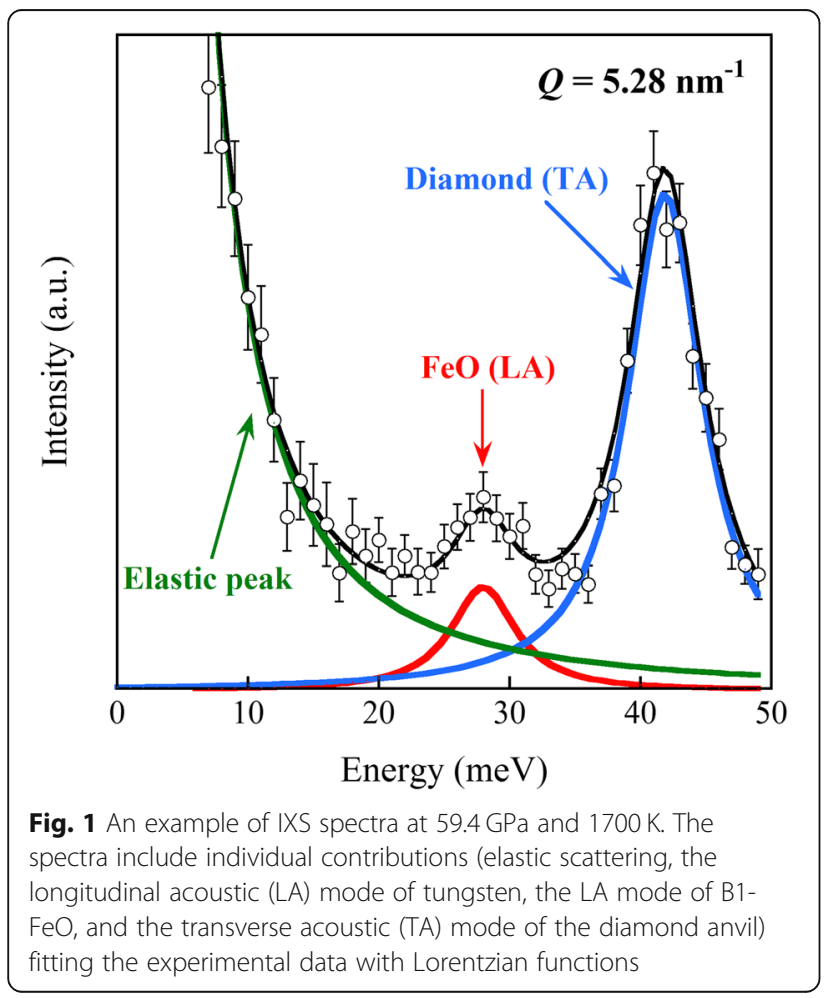

the photons was obtained by fitting a Lorentzian function to the peak. The longitudinal sound velocity $\left(V_{P}\right)$ was calculated by fitting the phonon dispersion (Fig. 3) with a function,

$$
\begin{aligned}
E[\mathrm{meV}]= & 4.192 \times 10^{-4} V_{p}[\mathrm{~m} / \mathrm{s}] \\
& \times Q_{\max }\left[\mathrm{nm}^{-1}\right] \sin \left[\frac{\pi}{2} \frac{Q\left[\mathrm{~nm}^{-1}\right]}{Q_{\max }\left[\mathrm{nm}^{-1}\right]}\right],
\end{aligned}
$$

where $E$ and $Q$ are the energy and momentum transfer, respectively, and $Q_{\max }$ is a free parameter.

Our result at $4 \mathrm{GPa}$ is compared to those of previous studies under ambient conditions in Fig. 4. Considering the pressure dependence of $V_{P}$, the velocity found in this study at $4 \mathrm{GPa}$ is approximately $0.1 \mathrm{~km} / \mathrm{s}$ larger than that of the ambient data. The velocities are in the range of 6.4-6.7 km/s except in the study of Badro et al. (2007). Sumino et al. (1980) reported that the density and velocity of wüstite increased with the decreasing fraction of iron deficiency in the wüstite: $\mathrm{Fe}_{0.92} \mathrm{O}$ had $\rho=5.68 \mathrm{~g} /$ $\mathrm{cm}^{3}$ and $V_{P}=6.54 \mathrm{~km} / \mathrm{s}$ and $\mathrm{FeO}$ had $\rho=5.86 \mathrm{~g} / \mathrm{cm}^{3}$ and $V_{P}=6.63 \mathrm{~km} / \mathrm{s}$. Our result is consistent with the trend reported by Sumino et al. (1980). The variation of $\rho-V_{P}$ shown in Fig. 4 may be caused by differences in the sample conditions and/or measurement techniques.

The measured velocities are plotted as a function of density in Fig. 5. For comparison, data from previous studies (Badro et al. 2007; Wicks et al. 2017) are also plotted. The $V_{P}-\rho$ relationship for our study shows a similar trend that of Badro et al. (2007), whereas the trend found by Wicks et al. (2017) is different with a density (pressure) dependence that is much smaller than that seen in our data. Our study and that of Badro et al. (2007) calculated $V_{P}$ based on the phonon dispersion obtained via the IXS measurement. Conversely, Wicks et al. (2017) conducted nuclear resonance inelastic scattering (NRIXS) experiments and acquired the Debye sound velocity using the low-energy regions of the phonon density of states. There is a possibility that the differences in the techniques used contributed to the discrepancies between the high-pressure data.

The $V_{P}-\rho$ data at ambient temperature in this study show a linear relationship, following Birch's law (Birch 1961), which is expressed as 


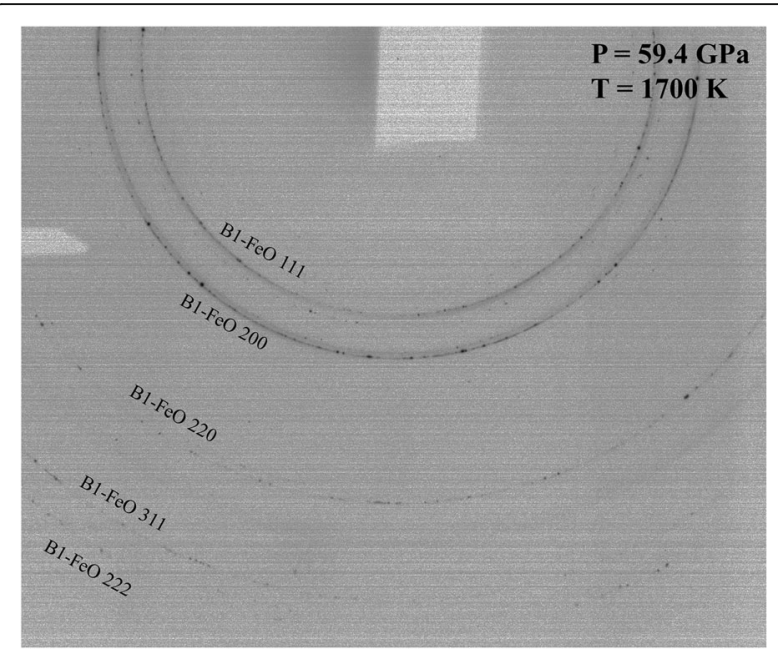

Fig. 2 X-ray pattern at 59.4 GPa and $1700 \mathrm{~K}$

$$
V_{P}[\mathrm{~km} / \mathrm{s}]=1.55(1) \times \rho\left[\mathrm{g} / \mathrm{cm}^{3}\right]-2.03(8) .
$$

Assuming that the $V_{P}-\rho$ data at $1700 \mathrm{~K}$ also follow Birch's law, the linear relationship at $1700 \mathrm{~K}$ can be expressed as

$$
V_{P}[\mathrm{~km} / \mathrm{s}]=1.61(1) \times \rho\left[\mathrm{g} / \mathrm{cm}^{3}\right]-2.82(10) .
$$

Assuming a linear temperature dependence, the isothermal $V_{P}-\rho$ fitting line at a temperature $\mathrm{T}[\mathrm{K}]$ can be expressed as

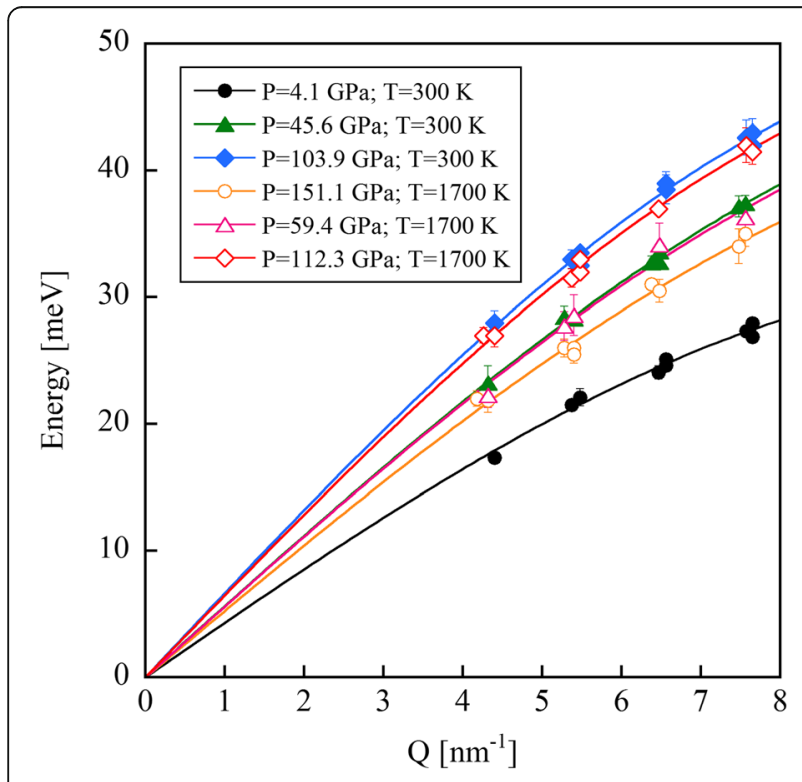

Fig. $3 L A$ phonon dispersion of wüstite under different experimental conditions. Solid curves are the results of sine curve fitting

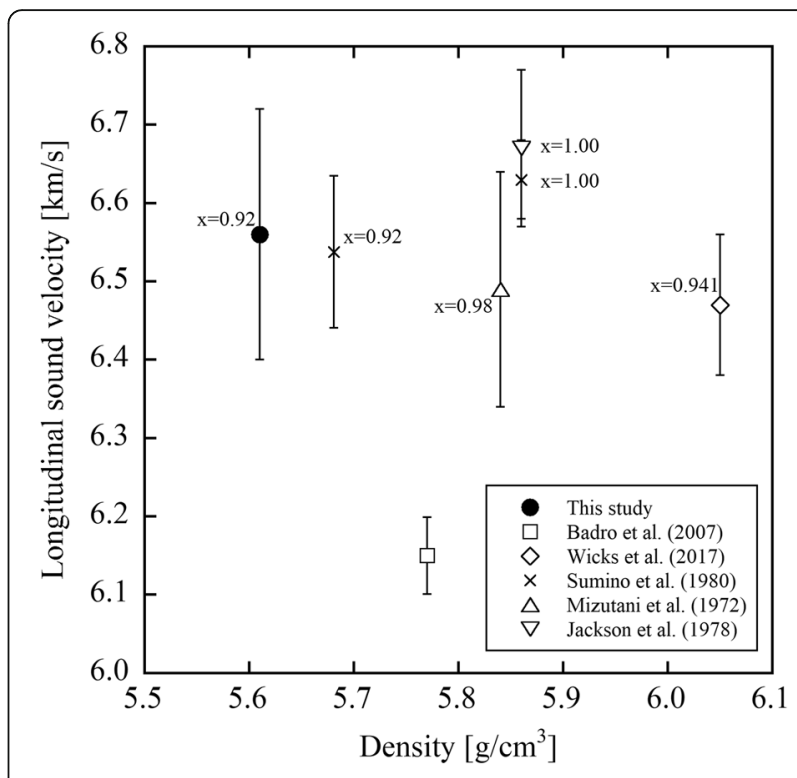

Fig. 4 Comparison of the $V_{p}-\rho$ relationships of $\mathrm{FeO}$ under ambient and low pressures. The values next to symbols indicate the percentage of $\mathrm{Fe}$ in $\mathrm{Fe}_{\mathrm{x}} \mathrm{O}$

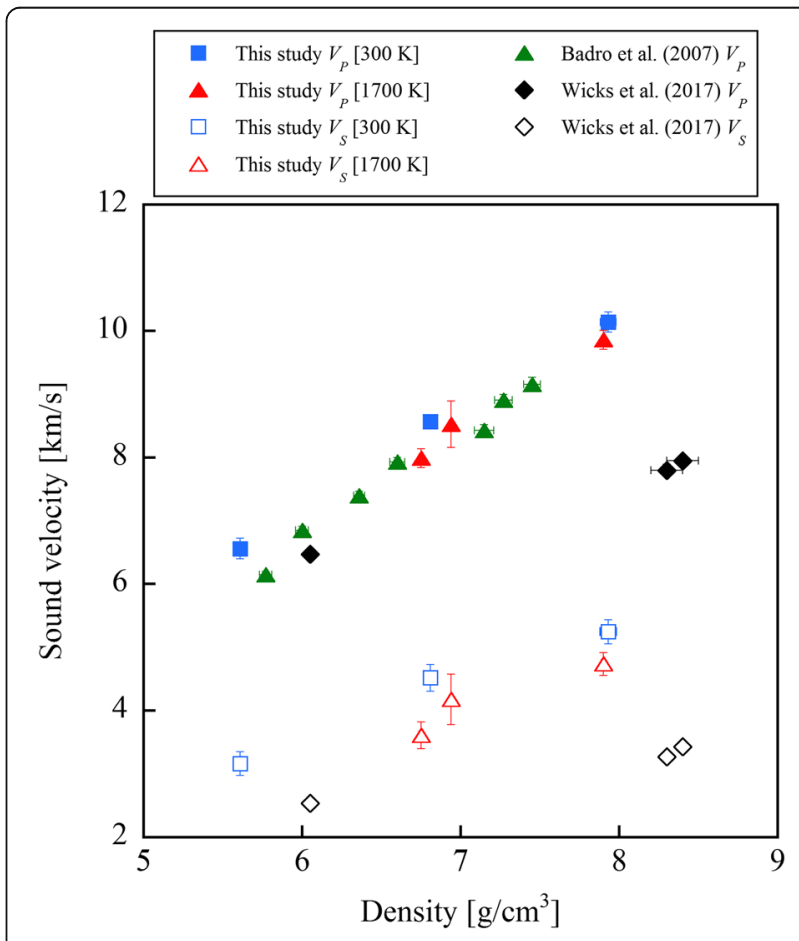

Fig. 5 Sound velocities of wüstite at $300 \mathrm{~K}$ and $1700 \mathrm{~K}$ as a function of density. For comparison, velocities at $300 \mathrm{~K}$ reported by Badro et al. (2007) and Wicks et al. (2017) are plotted 


$$
\begin{aligned}
V_{P}(\rho, T)= & {\left[1.55(1)+4.3(7) \times 10^{-5} \times(T-300)\right] } \\
& \times \rho-2.03(8)-5.6(6) \times 10^{-4} \\
& \times(\mathrm{T}-300) .
\end{aligned}
$$

Transverse sound velocities $\left(V_{S}\right)$ of wüstite were obtained such that

$$
V_{S}=\sqrt{\frac{3}{4}\left(V_{P}{ }^{2}-\frac{K_{S}}{\rho}\right)} .
$$

$K_{S}$ is the adiabatic bulk modulus and is calculated as

$$
K_{S}=(1+\alpha \gamma T) K_{T},
$$

where $\alpha$ is the coefficient of thermal expansion (Seagle et al. 2008), $\gamma$ is the Grüneisen parameter, and $K_{T}$ is the isothermal bulk modulus (Fischer et al. 2011). The thermal expansion of $\mathrm{FeO}$ is known to be approximately independent of temperature above $1620 \mathrm{~K}$ (Seagle et al. 2008). The coefficient of thermal expansion at high pressure is calculated using the following form: $\alpha=\alpha_{0}(V /$ $\left.V_{O}\right)^{\xi}$ (where $\alpha_{O}=4.22 \times 10^{-5} \mathrm{~K}^{-1}, V_{O}=84.75{ }^{3}$, and $\xi$ $=6.0$; Seagle et al. 2008).

The $V_{S}-\rho$ relationship in this study also follows Birch's law and the linear relationships at $300 \mathrm{~K}$ and $1700 \mathrm{~K}$ are described as

$$
\begin{aligned}
& V_{S}[\mathrm{~km} / \mathrm{s}]=0.90(2) \times \rho\left[\mathrm{g} / \mathrm{cm}^{3}\right]-1.82(11), \\
& V_{S}[\mathrm{~km} / \mathrm{s}]=0.93(2) \times \rho\left[\mathrm{g} / \mathrm{cm}^{3}\right]-2.58(13) .
\end{aligned}
$$

Applying the same isothermal fitting to $V_{S}-\rho$, the following equation is obtained:

$$
\begin{aligned}
V_{S}(\rho, T)= & {\left[0.90(2)+2.1(14) \times 10^{-5} \times(T-300)\right] } \\
& \times \rho-1.82(11)-5.4(11) \times 10^{-4} \\
& \times(\mathrm{T}-300) .
\end{aligned}
$$

According to Fig. 4, the misfit in $V_{P}$ at $300 \mathrm{~K}$ between the study of Badro et al. (2007) and the other studies is approximately $0.3-0.4 \mathrm{~km} / \mathrm{s}$. This misfit is large compared to the estimated errors. Even though there are several possibilities for this misfit, the differences between this study and that of Badro et al. (2007) can be, at least qualitatively, understood by considering distinctions in the spectrometer operations. Even though the IXS spectrometers at both SPring-8 and ESRF operate in backscattering geometry and scan energies by varying the temperature of the main monochromator, technical aspects directly influence the temporal stability of the elastic energy and the data collection. Another significant difference is in the number and relative positions used to constrain the phonon dispersion within the first Brillouin zone. We used four points in the $4-8 \mathrm{~nm}^{-1}$ range, while Badro et al. (2007) used five points in the 4-12 $\mathrm{nm}^{-1}$ range. As described in Bosak et al. (2007), the $V_{P}$ value is sensitive to the dispersion fitting procedure and the $Q$-settings can affect the derived velocity.

Figure 5 shows that the $V_{P}$ and $V_{S}$ values at high pressure reported by Wicks et al. (2017) are approximately 20-30\% smaller than the velocities in our study and that of Badro et al. (2007). The misfit is clearly larger than the estimated errors. For the velocity measurement, Wicks et al. (2017) conducted NRIXS, which probes the partial projected phonon density of states of materials containing Mössbauer resonant isotopes (e.g., $\left.{ }^{57} \mathrm{Fe}\right)$. The Debye velocity can be obtained via a parabolic fit of the low-energy portions of the phonon density of states. Combining the measured Debye velocity with an equation of state (density and adiabatic bulk modulus), $V_{P}$ and $V_{S}$ can be determined. In other words, the $V_{P}$ and $V_{S}$ values are dependent on the choice of the equation of state used for the data analysis. In terms of the velocities at high pressure, Wicks et al. (2017) used an approximately $20 \%$ smaller bulk modulus than the equation of state reported by Fischer et al. (2011). This implies that Wicks et al. (2017) underestimated the $V_{P}$ and $V_{S}$ values at high pressure.

The sound velocities of wüstite and the lower mantle minerals as a function of pressure along the representative mantle geotherm (Brown and Shankland 1981) are shown in Fig. 6. The velocities of $\left(\mathrm{Mg}_{0.94}, \mathrm{Fe}_{0.06}\right) \mathrm{SiO}_{3}$ bridgimanite and $\left(\mathrm{Mg}_{0.79}, \mathrm{Fe}_{0.21}\right) \mathrm{O}$ ferropericlase have been reported by Murakami et al. (2007). Under lower mantle conditions, the $V_{P}$ and $V_{S}$ values of wüstite are lower than those of bridgimanite and ferropericlase.

The calculated $V_{P}$ and $V_{S}$ values of wüstite along the mantle geotherm are compared to PREM and ULVZs in Fig. 7. The $V_{P}$ and $V_{S}$ values of wüstite are $19 \%$ and $27 \%$ lower than those of PREM under CMB conditions $(P=$ $136 \mathrm{GPa}$ and $T=2450 \mathrm{~K})$, respectively. The velocity reduction at the ULVZs $\left(V_{P}, \sim 5-20 \%\right.$ and $\left.V_{S}, \sim 10-30 \%\right)$ can be explained by the existence of wüstite. The $\mathrm{FeO}$ velocity in this study at $\mathrm{CMB}$ conditions is larger than that found in the study of Wicks et al. (2017). This implies that a much higher amount of $\mathrm{FeO}$ is needed to fit the ULVZ velocity. The addition of wüstite would cause not only a velocity decrease but also a drastic density increase. It is difficult to explain all ULVZs by FeO enrichment. An extremely large increase in density (20-25\%) accompanying the ULVZ has been reported below the Philippine islands (Idehara 2011). Some of the increase in the ULVZ density could be explained by the existence of wüstite at the base of the lower mantle.

\section{Conclusions}

We measured the longitudinal sound velocity and density of wüstite up to $112.3 \mathrm{GPa}$ and $1700 \mathrm{~K}$ using IXS and 

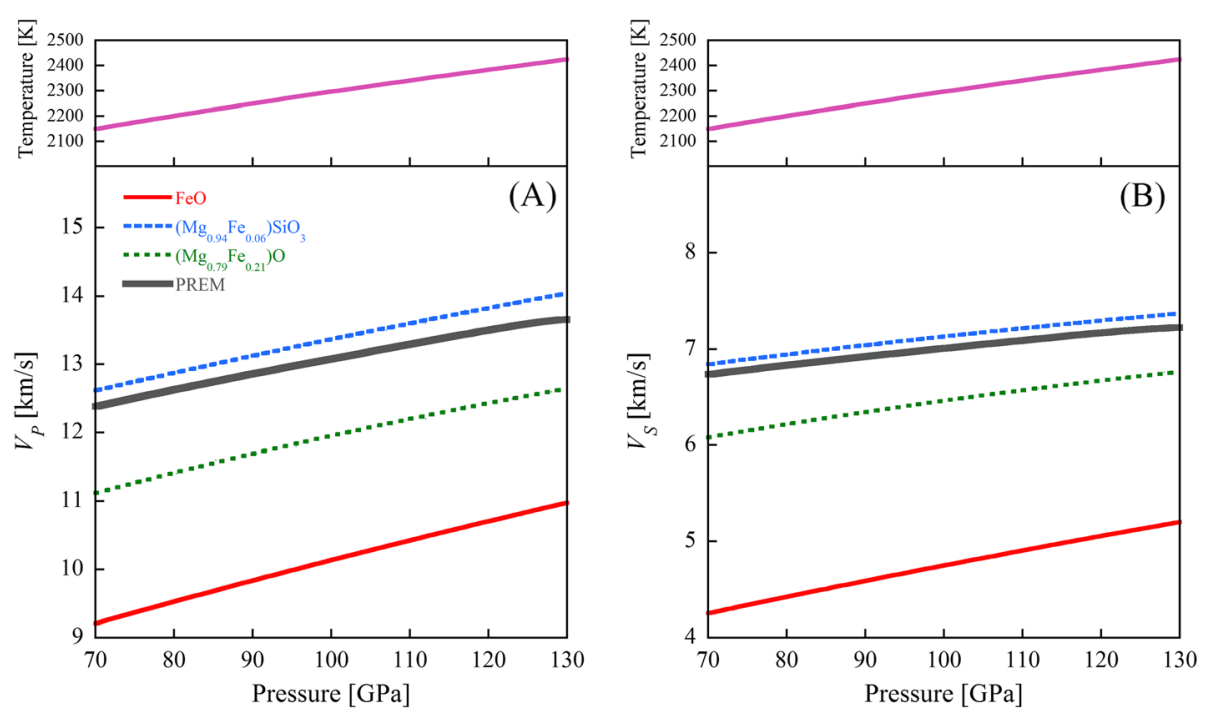

Fig. 6 Sound velocities of wüstite under lower mantle conditions. The $V_{p}(\mathbf{a})$ and $V_{S}(\mathbf{b})$ profiles were calculated along the mantle geotherm (Brown and Shankland 1981). The red solid line represents the B1-FeO values obtained in this study. The dashed and dotted lines represent bridgmanite $\left(X_{M g}=0.94\right)$ and magnesiowüstite $\left(X_{M g}=0.79\right)$, respectively (Murakami et al. 2007). The bold line represents PREM

XRD. Because the sound velocity of wüstite is the slowest of the major mantle minerals in the lower mantle, a wüstite enrichment could cause a low-velocity anomaly, such as that observed in ULVZs. Therefore, wüstite likely plays an important role in generating the heterogeneities observed seismologically in the deep lower mantle.

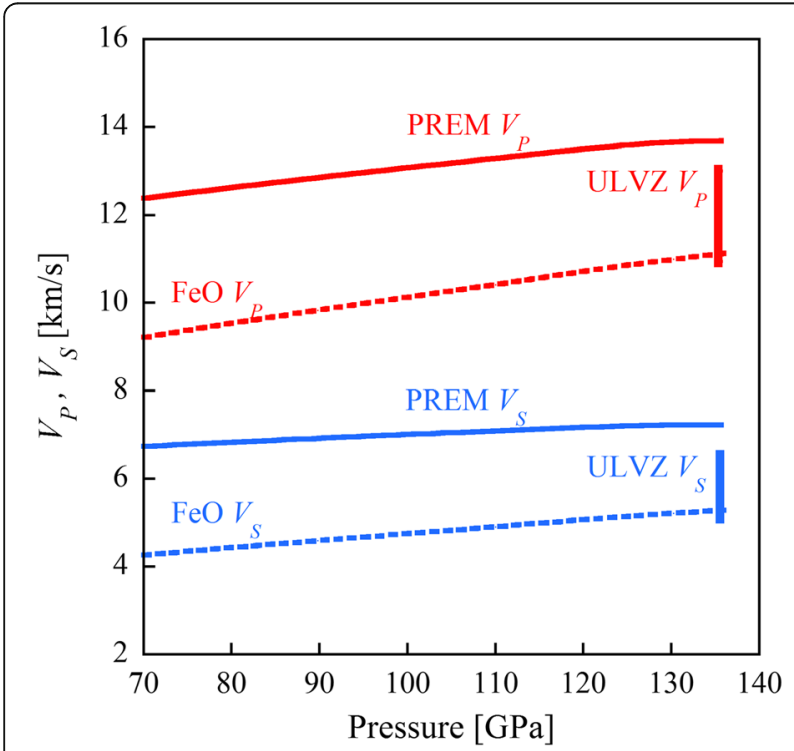

Fig. 7 Comparison of the sound velocities of wüstite with those of PREM and ULVZs. The $V_{P}$ and $V_{S}$ profiles of wüstite are shown by broken lines as a function of pressure along the mantle geotherm (Brown and Shankland 1981). The $V_{P}$ and $V_{S}$ profiles for PREM are plotted by solid lines with those of the ULVZs

\section{Abbreviations}

ULVZ: Ultra low-velocity zone; CMB: Core-mantle boundary; LHDAC: Laserheated diamond-anvil cell; BIF: Banded-iron formation; DAC: Diamond-anvil cell; IXS: Inelastic X-ray scattering; FWHM: Full width at half maximum; XRD: X-ray diffraction; LA: Longitudinal acoustic peak; TA: Transverse acoustic peak; PREM: Preliminary reference Earth model

\section{Acknowledgements}

The synchrotron radiation experiments were performed under contract with SPring-8 (proposal nos. 2016A1171, 2016A1180, 2016B1112, 2016B1419, 2017A1350, 2017A1474, 2017B1264, and 2019A1116).

\section{Authors' contributions}

TS proposed the topic and conceived and designed the study. RT, HF, SK, AS, $S T, H U$ and $A B$ carried out the experimental study and analyzed the data. EO collaborated with the corresponding author (TS) in the construction of the manuscript. All authors read and approved the final manuscript.

\section{Funding}

This work was supported by JSPS Grants-in-Aid for Scientific Research Grant Numbers $16 \mathrm{H} 01112$ and $17 \mathrm{H} 04860$ to TS and $15 \mathrm{H} 05748$ to EO.

\section{Availability of data and materials}

The data used are reported in the manuscript tables. All original data are available from the corresponding author on request.

\section{Competing interests}

The authors declare that they have no competing interests.

\section{Author details}

${ }^{1}$ Department of Earth Science, Graduate School of Science, Tohoku University, Sendai, Miyagi 980-8578, Japan. ${ }^{2}$ Graduate School of Material Science, University of Hyogo, Kamigori, Hyogo 678-1297, Japan. ${ }^{3}$ Materials Dynamics Laboratory, RIKEN SPring-8 Center, Sayo, Hyogo 679-5148, Japan. ${ }^{4}$ Frontier Research Institute for Interdisciplinary Sciences, Tohoku University, Sendai 980-8578, Japan. ${ }^{5}$ Center for Synchrotron Radiation Research, Japan Synchrotron Radiation Research Institute (JASRI), 1-1-1 Kouto, Sayo, Hyogo 679-5198, Japan. 
Received: 23 May 2019 Accepted: 1 May 2020

Published online: 08 June 2020

\section{References}

Akahama Y, Kawamura H (2004) High-pressure Raman spectroscopy of diamond anvils to $250 \mathrm{GPa}$ : method for pressure determination in the multimegabar pressure range. J Appl Phys 96:3748-3751. https://doi.org/10.1063/1.1778482

Badro J, Fiquet G, Guyot F, Gregoryanz E, Occelli F, Antonangeli D, d'Astuto M (2007) Effect of light elements on the sound velocities in solid iron: implications for composition of Earth's core. Earth Planet Sci Lett 254:233238. https://doi.org/10.1016/j.epsl.2006.11.025

Baron AQR, Tanaka Y, Goto S, Takeshita K, Matsushita T, Ishikawa T (2000) An Xray scattering beamline for studying dynamics. J Phys Chem Solids 61:461465. https://doi.org/10.1016/S0022-3697(99)00337-6

Birch F (1961) Composition of the Earth's mantle. Geophys J R Astron Soc 4:295311. https://doi.org/10.1111/j.1365-246X.1961.tb06821.x

Bosak A, Krisch M, Fischer I, Huotari S, Monaco G (2007) Inelastic x-ray scattering from polycrystalline materials at low momentum transfer. Phys Rev B 75: 064106. https://doi.org/10.1103/PhysRevB.75.064106

Brown JM, Shankland TJ (1981) Thermodynamic parameters in the Earth as determined from seismic profiles. Geophys J R Astron Soc 66:579-596. https://doi.org/10.1111/j.1365-246X.1981.tb04891.x

Dobson DP, Brodholt JD (2005) Subducted banded iron formations as a source of ultralow-velocity zones at the core-mantle boundary. Nature 434:371-374. https://doi.org/10.1038/nature03430

Fei Y, Mao H (1994) In situ determination of the NiAs phase of FeO at high pressure and temperature. Science 266:1678-1680. https://doi.org/10.1126/ science. 266.5191 .1678

Fischer RA, Campbell AJ, Shofner GA, Lord OT, Dera P, Prakapenka VB (2011) Equation of state and phase diagram of FeO. Earth Planet Sci Lett 304:496502. https://doi.org/10.1016/j.epsl.2011.02.025

Fukui H, Sakai T, Sakamaki T, Kamada S, Takahashi S, Ohtani E, Baron AQR (2013) A compact system for generating extreme pressures and temperatures: An application of laser-heated diamond anvil cell to inelastic X-ray scattering. Rev Sci Instrum 84:113902. https://doi.org/10.1063/1.4826497

Hutko AR, Lay T, Revenaugh J (2009) "Localized double-array stacking analysis of PCP: D" and ULVZ structure beneath the Coco plate, Mexico, central Pacific, and north Pacific. Phys Earth Planet Inter 173:60-74. https://doi.org/10.1016/j. pepi.2008.11.003

Idehara K (2011) Structural heterogeneity of an ultra-low-velocity zone beneath the Philippine islands: implications for core-mantle chemical interactions induced by massive partial melting at the bottom of the mantle. Phys Earth Planet Inter 184:80-90. https://doi.org/10.1016/j.pepi.2010.10.014

Idehara K, Yamada A, Zhao D (2007) Seismological constraints on the ultralow velocity zones in the lowermost mantle from core-reflected waves. Phys Earth Planet Inter 165:25-46. https://doi.org/10.1016/j.pepi.2007.07.005

Ishikawa D, Uchiyama H, Tsutsui S, Fukui H, Baron AQR (2013) Compound focusing for hard-X-ray inelastic scattering, in: Proceedings of SPIE - The International Society for Optical Engineering. https://doi.org/10.1117/12. 2023795

Jackson et al (2006) Single-crystal elasticity and sound velocities of $\left(\mathrm{Mg}_{0.94} \mathrm{Fe}_{0.06}\right) \mathrm{O}$ ferropericlase to $20 \mathrm{GPa}$. J Geophys Res 111:B09203. https:// doi.org/10.1029/2005JB004052

Knittle E, Jeanloz R (1991) Earth's core-mantle boundary: results of experiments at high pressures and temperatures. Science 251:1438-1443. https://doi.org/10. 1126/science. 251.5000 .1438

Labrosse S, Hernlund JW, Coltice N (2007) A crystallizing dense magma ocean at the base of the Earth's mantle. Nature 450:866-869. https://doi.org/10.1038/ nature06355

Lin et al (2006) Sound velocities of ferropericlase in the Earth's lower mantle. Geophys Res Lett 33:L22304. https://doi.org/10.1029/2006GL028099

Matsui M, Higo Y, Okamoto Y, Irifune T, Funakoshi K (2012) Simultaneous sound velocity and density measurements of $\mathrm{NaCl}$ at high temperatures and pressures: application as a primary pressure standard. Am Mineral 97:1670-1675

McCammon CA, Liu L (1984) The effects of pressure and temperature on nonstoichiometric wüstite, $\mathrm{Fe}_{\mathrm{x}} \mathrm{O}$ : the iron-rich phase boundary. Phys Chem Miner 10:106-113. https://doi.org/10.1007/BF00309644

Mizutani H, Hamano Y, Akimoto S (1972) Elastic-wave velocities of polycrystalline stishovite J Geophys Res 77:3744-3749. https://doi.org/10.1029/ JB077i020p03744
Murakami M, Sinogeikin SV, Hellwig H, Bass JD, Li J (2007) Sound velocity of $\mathrm{MgSiO}_{3}$ perovskite to Mbar pressure. Earth Planet Sci Lett 256:47-54. https:// doi.org/10.1016/j.epsl.2007.01.011

Ohta K, Cohen RE, Hirose K, Haule K, Shimizu K, Ohishi Y (2012) Experimental and theoretical evidence for pressure-induced metallization in FeO with rocksalttype structure. Phys Rev Lett 108:026403

Ohta K, Fujino K, Kuwayama Y, Kondo T, Shimizu K, Ohishi Y (2014) Highly conductive iron-rich (Mg,Fe)O magnesiowüstite and its stability in the Earth's lower mantle. J Geophys Res Solid Earth 119:4656-4665. https://doi.org/10. 1002/2014JB010972

Ozawa H, Hirose K, Ohta K, Ishii H, Hiraoka N, Ohishi Y, Seto Y (2011a) Spin crossover, structural change, and metallization in NiAs-type FeO at high pressure. Phys Rev B 84:134417

Ozawa H, Takahashi F, Hirose K, Ohishi Y, Hirao N (2011b) Phase transition of FeO and stratification in Earth's outer core. Science 334:792-794. https://doi.org/ $10.1126 /$ science. 1208265

Rost S, Garnero EJ, Stefan W (2010) Thin and intermittent ultralow-velocity zones. J Geophys Res Solid Earth 115:B06312. https://doi.org/10.1029/2009JB006981

Sakai T, Ohtani E, Hirao N, Ohishi Y (2011) Equation of state of the NaCl-B2 phase up to 304 GPa. J Appl Phys 109:084912

Sakairi T, Sakamaki T, Ohtani E, Fukui H, Kamada S, Tsutsui S, Uchiyama H, Baron AQR (2018) Sound velocity measurements of hcp Fe-Si alloy at high pressure and high temperature by inelastic X-ray scattering. Am Mineral 103:85-90

Sakamaki T, Ohtani E, Fukui H, Kamada S, Takahashi S, Sakairi T, Takahata A, Sakai T, Tsutsui S, Ishikawa D, Shiraishi R, Seto Y, Tsuchiya T, Baron AQR (2016) Constraints on Earth's inner core composition inferred from measurements of the sound velocity of hcp-iron in extreme conditions. Sci Adv 2:e1500802. https://doi.org/10.1126/sciadv.1500802

Seagle CT, Heinz DL, Cambell AJ, Prakapenka VB, Wanless ST (2008) Melting and thermal expansion in the Fe-FeO system at high pressure. Earth Planet Sci Lett 265:655-665. https://doi.org/10.1016/j.epsl.2007.11.004

Stixrude L, Lithgow-Bertelloni C (2007) Influence of phase transformation on lateral heterogeneity and dynamics in Earth's mantle. Earth Planet Sci Lett 263:45-55

Sumino Y, Kumazawa M, Nishizawa O, Pluschkell W (1980) The elastic constants of single crystal $\mathrm{Fe}_{1-\mathrm{x}} \mathrm{O}, \mathrm{MnO}$ and the elasticity of stoichiometric magnesiowüstite. J Phys Earth 28:475-495

Takahashi S, Ohtani E, Sakamaki T, Kamada S, Fukui H, Tsutsui S, Uchiyama H, Ishikawa D, Hirao N, Ohishi Y, Baron AQR (2019) Sound velocity of Fe3C at high pressure and high temperature determined by inelastic $X$-ray scattering. C R Geoscience 351:190-196

Thorne M, Garnero E (2004) Inferences on ultralow-velocity zone structure from a global analysis of SPdKS waves. J Geophys Res 109:B08301. https://doi.org/10 1029/2004JB003010

Wicks JK, Jackson JM, Sturhahn W (2010) Very low sound velocities in iron-rich (Mg,Fe)O: implications for the core-mantle boundary region. Geophys Res Lett 37:L15304. https://doi.org/10.1029/2010GL043689

Wicks JK, Jackson JM, Sturhahn W, Zhang D (2017) Sound velocity and density of magnesio wüstite: implications for ultralow-velocity zone topography. Geophys Res Lett 44:2148-2158. https://doi.org/10.1002/2016GL071225

Yagi T, Suzuki T, Akimoto S (1985) Static composition of wüstite $\left(\mathrm{Fe}_{0.98} \mathrm{O}\right)$ to 120 GPa. J Geophys Res 90:8784-8788. https://doi.org/10.1029/JB090iB10p08784

\section{Publisher's Note}

Springer Nature remains neutral with regard to jurisdictional claims in published maps and institutional affiliations. 